\title{
Biochemical studies on malathion resistance, inheritance and association of carboxylesterase activity in brown planthopper, Nilaparvata lugens complex in Peninsular Malaysia.
}

\begin{abstract}
Two sympatric populations of brown planthopper $(\mathrm{BPH})$, one from rice and the other from Leersia hexandra were collected from each of five locations in Malaysia. All the tested malathion-resistant individuals of the rice $\mathrm{BPH}$ population and $\mathrm{F} 1$ generation (cross between malathion-resistant [usually caught on rice] and malathion-susceptible [usually caught on Leersia]) showed high esterase activity, while all malathion-susceptible individuals on L. hexandra showed low esterase activity. In the F2 generation, all the individuals tested against malathion were approximately $75 \%$ resistant and $25 \%$ susceptible and the inheritance pattern of esterase activity (high and low esterase activity) segregated in the same manner to a 3:1 ratio. This confirms that resistance to malathion is mono-factorial and inheritance pattern of esterase activity is also linked to malathion resistance. Carboxylesterase or total esterase activity in BPH is inherited in a simple Mendelian fashion that is encoded by a single dominant gene. For the total esterase assay, average esterase activity levels in the riceinfesting population ranged from 17.64 to $19.37 \mathrm{nmoles} 1$-napthol $/ \mathrm{mg}$ protein while that in the Leersia-infesting population ranged from 5.29 to $6.11 \mathrm{nmoles} 1$-napthol/mg protein. In terms of esterase activity, the two sympatric Ni-laparvata lugens populations separated into two distinct groups. Results based on the tube color intensity test showed $96 \%$ and $98 \%$ resistant and susceptible individuals were present in the rice- and Leersia-infesting populations, respectively. In a filter paper test, the rice-infesting population had $94 \%$ with high esterase activity while the Leersia-infesting population had $96 \%$ with low esterase activity.
\end{abstract}

Keyword: Brown planthopper; Carboxylesterase assay; Inheritance study; Insecticide resistance; Rice. 